\title{
Multi-Subject Cooperative Participation in Rural Governance Research
}

\author{
Yufeng Jiang \\ School of Public Administration/Emergency Management, Jinan University, Guangzhou, China \\ Email: jiangyufeng2018@stu2018.jnu.edu.cn
}

How to cite this paper: Jiang, Y. F. (2021). Multi-Subject Cooperative Participation in Rural Governance Research. Open Journal of Social Sciences, 9, 218-227.

https://doi.org/10.4236/jss.2021.93014

Received: February 5, 2021

Accepted: March 15, 2021

Published: March 18, 2021

Copyright $\odot 2021$ by author(s) and Scientific Research Publishing Inc. This work is licensed under the Creative Commons Attribution International License (CC BY 4.0).

http://creativecommons.org/licenses/by/4.0/

\begin{abstract}
In recent years, the main body of rural governance in China has gradually changed from single to diversification, but the main body of governance has not formed an orderly and reasonable governance structure. The paper adopts the collaborative governance theory as the analytical framework, starting from the main body of rural governance, analyzes the realistic dilemma among the multiple subjects of rural governance from the four aspects of collaborative governance's (value goals, system design, behavior selection and condition). Finally, according to the problems, the countermeasures to solve the coordinated participation of multi-subjects in rural governance are proposed.
\end{abstract}

\section{Keywords}

Rural Revitalization, Main Body of Governance, Cooperative Governance, Rural Governance

\section{Introduction}

As an important part of grassroots governance, the effectiveness of rural governance has always been the top priority of China. In January 2018, the Central Committee of the Communist Party of China and the State Council issued the "Opinions on the Implementation of the Rural Revitalization Strategy", which stated that effective governance is the basis for rural revitalization, and a modern social governance mechanism featuring party committee leadership, government responsibility, social coordination, public participation, and the rule of law must be established ${ }^{1}$. The Fifth Plenary Session of the 19th Central Committee of the Communist Party of China proposed "significantly improve social governance,

${ }^{1}$ The Information Office of the State Council of the People's Republic of China. (2018, Feb, 4) Policy Interpretation of Opinions on Implementing the Strategy of Rural Revitalization. Government website of the People's Republic of China 2018-02-06. Retrieved December 25, 2020 from: http://www.gov.cn/zhengce/2018-02/04/content_5263807.htm. 
especially the level of grassroots governance during the 14th Five-Year Plan period". Chinese rural society is undergoing rapid transformation, and the social structure, social relations and the values of villagers have undergone tremendous changes, which have impacted the traditional governance pattern in the countryside. The social problems, social contradictions and social needs of the rural society have shown different characteristics. The dual structure of urban and rural areas has gradually been broken, and the public affairs and social problems in the countryside have changed. In addition, economic development has led to a diversified interest in rural society. For a long time, the main body of rural governance in China has been manifested as a ternary power structure composed of the party's grassroots organizations, the government, and villagers' organizations. In terms of means of production, wealth and The huge difference in the level of education in possession has led to the emergence of more classes of rural residents, including business managers, migrant workers, industrial and commercial households, and private enterprises. Under such circumstances, the stakeholders of rural governance activities have become complex and diverse. The governance structure of the ternary authority of rural society has been broken. However, the various newly emerged subjects still have not formed a reasonable and effective governance model, resulting in low efficiency of rural governance and hindering rural revitalization. Therefore, rural society urgently needs to establish a scientific and reasonable governance structure.

\section{The Division of the Main Body of Rural Governance}

The main body of rural governance refers to the organizations, institutions and individuals that play important roles in rural governance (Xu, 2002). Chinese scholars define and classify the concept of rural governance subject from the relationship between state governance and local governance, but so far there is no unified view. The main classification of them are: 1) three types: government agencies, non-governmental organizations and individual villagers (Zhang, 2017); 2) four types: township government, village party branches, village committees, and villagers' congresses ( $\mathrm{Li}, 2015) ; 3$ ) two types: institutional subjects and non-institutional subjects (Yin, 2016). With the changes and development of the times, the rural ternary authority structure is undergoing evolution: the township government is no longer the absolute power of rural governance, and the village committee and the village party branch no longer simply act as agents of the township government; Rural social organizations spontaneously established with economic progress, rural elites represented by wealthy experts and migrant workers returning home to start their own businesses, together with township governments, and villagers' self-governing organizations constitute the pluralistic main body pattern of rural governance in China today. Synthesizing the new entities emerging in rural society at this stage, this paper divides the rural governance entities into the following four levels: 1) national level: the township government, 2) village level: the villagers' committees, village party committees and other grassroots democratic self-governing organizations, 3) social level: 
various non-governmental organizations emerging in the rural society, 4) individual level of villagers: ordinary villagers and village elites.

\section{Analysis of Rural Governance Dilemma under the Framework of Collaborative Governance Theory}

In fact, the phenomenon of decentralization, departmentalization, and fragmentation of national governance have led to a governance dilemma that weakened effectiveness of national governance is widespread in the world. Collaborative governance is a compound concept that responds to systemic governance dilemmas. It is based on synergy and governance theory and emphasizes the cooperation and coordination of multiple subjects to achieve the purpose of collaborative governance. The emergence of collaborative governance theory provides an excellent theoretical analysis framework for the same-level cross-departmental governance within the government, cross-level and cross-departmental collaborative governance within the government, collaborative governance between government and society. This article adopts the analytical framework of collaborative governance theory to analyze the differentiation and diversification of rights and goals among rural governance subjects. Starting from the framework of collaborative governance theory, rural governance is a typical and complex collaborative governance behavior. From the perspective of the participants, there are not only cross-departmental coordination between different competent departments of the same level of government, but also cross-level and cross-departmental governance coordination between different levels of government departments, such as township government and village committees, government and rural social organizations, government and individual villagers. With the development of economy, culture, and society, the main body of rural governance has surpassed the original ternary authority structure. The value orientation of rural governance is no longer simply to maintain rural social stability. In the context of rural revitalization, multiple value orientations are set and more goals are expected to achieve: build a new and systematically model of rural governance, improve the level of rural governance, promote the construction of new rural areas and the process of urbanization, and coordinate the coordinated development of urban and rural areas, and achieve the goal of a well-off society. Rural collaborative governance is a composite concept that involves the coordinated behavior of the governance system up and down, inside and outside, including four aspects: value goals, system design, behavior selection and conditions (showing in Figure 1).

\subsection{The Lack of Unified Value Goal Hinders the Willingness to Collaborate}

The value goal is the starting point of governance activities. From the perspective of collaborative governance, the consistent value goal is the source of motivation for the governance body to generate the willingness to collaborate. Barnard's organization theory said that organization is a collaborative system, and 


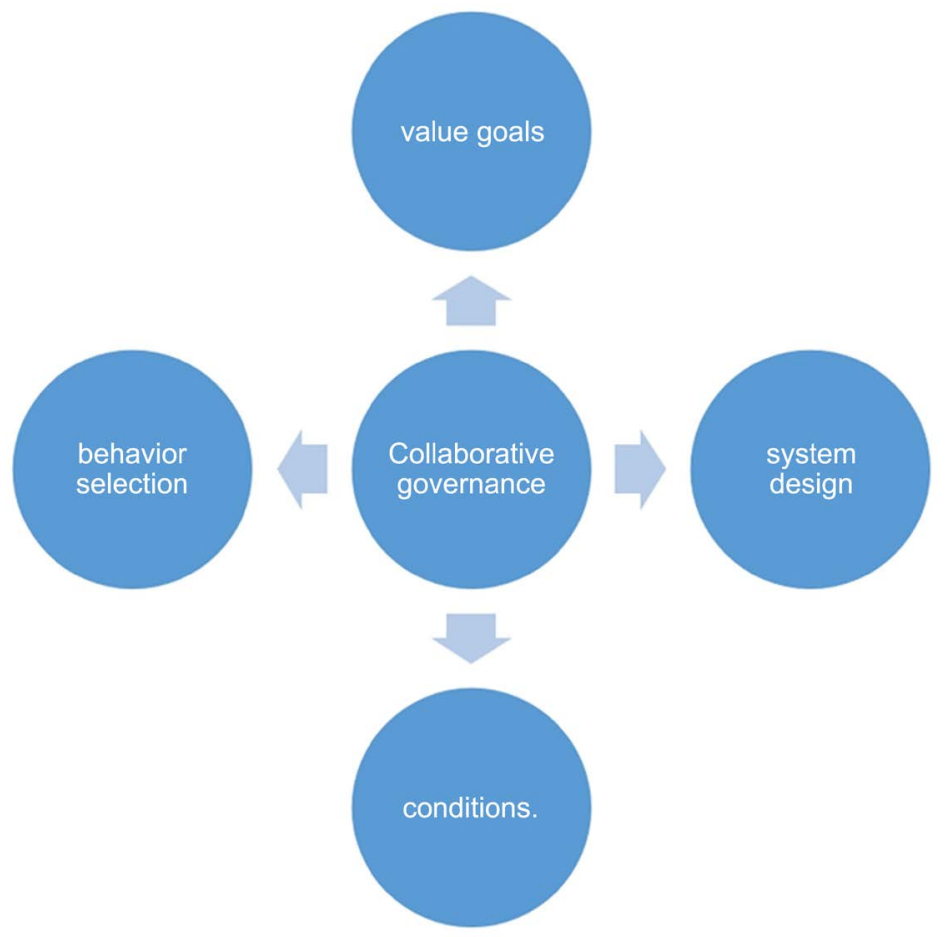

Figure 1. Logic diagram of mul-subjects involved in village governance collaborative.

the three basic elements of organization are willingness to collaborate, common goals and information exchange. In order to realize the coordination and cooperation of various subjects within the rural governance system, the first thing to be solved is the common goal and the willingness to cooperate. In the rural governance system, different governance entities have different values and demands, also difference cognitions for rural specific public affairs. In addition, the inequality of power status has led to the imperfect structure of the main body of rural governance, and the imbalance of power distribution has led to the lack of a unified goal between the subjects, and hindered the cooperate willingness of rural governance subjects. In the process of rural governance, the township government has most of the power in actual work. The long-standing "official standard" thought in Chinese society has caused village committees to generally rely on township governments. Due to the weak awareness of the legal system and the weak awareness of rights, democratic elections and supervision in grassroots democratic autonomy are mostly mere formalities. Clan forces have a profound influence on rural areas. Rural elites fight against each other to break rules, bribe elections, and refuse to approve election results. Migrant workers are turned away by those in power in the countryside, and it is difficult for them to exert their abilities and effectiveness. Due to the lack of democratic soil, rural social organizations struggle to survive in the process of rural governance.

\subsection{The Imperfect System Design Hinders Power of Coordination}

As with the modernization of national governance, the realization of moderniza- 
tion of rural governance fundamentally depends on system design. The grassroots mass autonomy system is a basic political system in our country, laws and regulations concerning rural governance are still relatively single now. It is difficult to provide an effective guarantee mechanism for multiple governance entities due to lack corresponding legal norms. The Law on the Organization of Village Committees only outlines the rights and responsibilities that villagers should have, lacks specific implementation procedures and regulations for new situations that have developed over time. The provisions of rights and obligations for the new rural social organizations and rural elites are vague. The lack of systems and incomplete laws have led to the blurring of the boundaries of rights and responsibilities of the multiple subjects of rural governance. There are many phenomena that hinder governance entities from participating in rural governance. For example, township governments directly intervened in rural elections, seriously intervening in rural autonomy, and eroded villagers and other subjects' right to govern. The administrative tasks imposed by the township government on the village committee go beyond the legal power of the township government. The village committee undertakes a lot of government work which will inevitably lead to the administrativeization of the village committee, which in turn leads to the bureaucratization of the village cadres. The administrativeization of village committees and the bureaucratization of village cadres make villagers' autonomy lack autonomy and democracy, to some extent, weaken the role of villagers' autonomy. The lack of rights leads to insufficient understanding of duties and responsibilities, the legitimacy of democratic elections, democratic decision-making, and democratic supervision is greatly compromised.

\subsection{The Choice of Behavior of Subjects Hinder the Transformation of Synergy}

The modernization of rural governance includes the dual meaning of the modernization of rural governance system and rural governance capabilities. On the basis of constructing a sound institutional system and governance system, the transformation of institutional advantages into governance efficiency requires high-quality human resources to implement and utilize systems. In the process of promoting the modernization of rural governance, as the main body of rural governance behavior, the poor governance capabilities of rural cadres, the weak sense of coordination, the individual political indifference of villagers, and the low willingness to participate that hinder the modernization of rural governance. Second, collaborative behavior is one of the ways to transform collaborative governance capabilities. In the governance system, to play the role of the system, we also need to pay attention to the behavior of individuals, especially the behavior of public managers. All individuals involved in rural governance can act actively and cooperate with each other to produce collaborative governance behavior. In fact, in the process of rural governance, due to the inequality of status and power, subjects often does not act or act slowly in rural collaborative gover- 
nance activities, and the effect of collaborative governance is greatly affected. Individuals participating in rural governance are not only lack of awareness of collaboration and cooperation, also lack of the ability to collaborate for their limited knowledge and horizons. Due to interest-related issues, various frictions and conflicts are often broken in the governance process.

\subsection{Poor Governance Conditions Lead to Lack of Support for Collaborative Activities}

The specific behaviors induced by the system depend on the specific historical background and initial conditions (Zhou \& Ai, 2010). The modernization of the national governance system and governance capabilities takes place in grand social background. Governance activities are bound to be restricted by social conditions and the environment, also the rural governance activities are. The external conditions and environment are the background and driving factors of the modernization of rural governance, also affect the trend of modernization of it. The realization of the collaborative governance of multiple subjects in rural areas relies on specific external conditions and environments, especially collaborative technical conditions. Under the rapid development of new technologies such as the Internet, cloud computing, big data and artificial intelligence, technical conditions have revolutionary catalytic effect on the collaboration and cooperation of rural governance. Although these profound technological changes have greatly promoted the progress of society, the modernization of national governance capabilities and governance systems, the use of technologies is still a problem for rural areas where wrapped up with traditional culture and surrounded by backward ideas. In addition, the external environment which including environment of political, economic, cultural and social also affect the cooperative behavior of rural governance subjects. At present, both rural elites and ordinary villagers are not positive for collaborative participation in rural governance. Rural society lacks the cultural tradition of participating in the governance of public affairs, as well as the motivation and channels. For not well-educated and less enthusiasm, grassroots democratic autonomy is often a mere formality. Rural social organizations and rural elites with the ability to participate are limited by limited channels. The inherent political inertia, economic development level and cultural traditions of rural society cannot provide effective support for the collaborative governance behavior of rural governance entities.

\section{The Path to Realize the Collaborative Participation of Multiple Subjects in Rural Governance under the Framework of Collaborative Governance Theory}

Based on the analytical framework of the collaborative governance theory, from the value objectives, system design, behavior selection and conditional environment of collaborative governance, the paths to achieve collaborative rural governance with multiple entities are follow: 


\subsection{Build a Community of Rural Governance Goals to Stimulate Collaborative Governance}

From the perspective of collaborative governance between different government departments, rural governance is a collaborative governance process involving multi-level and cross-department. Secondly, it is an interactive governance process between the government, society, and individuals. The ultimate goal of multiple subjects participating in rural governance is to achieve the modernization of the urban and rural grassroots governance system, improve the grassroots democratic consultation system, and achieve rural revitalization. "Governance" is different from "ruling". The authority of governance does not necessarily come from government agencies. It is a cooperation between the state and civil society, government and non-government, public institutions and private institutions, and compulsory and voluntary cooperation. A broader concept than governance (Yu, 2000). Rural governance is a process of interaction between the top and bottom. Common goals are confirmed through cooperation, negotiation, and partnership, and public affairs are governed by the authority of multiple interactions and a multi-subject and multi-center governance structure. First of all, it is necessary to establish trust relationship between the subjects of rural governance. Trust has important synergistic value which regulate the behavior of subjects and save governance costs. Second, optimize the cognition of public value by the main body of rural governance and strengthen the public value orientation. In the practice of public affairs, the values of justice, fairness and efficiency are complex, vague and competitive (Moore, 1995). Therefore, the main body of rural governance needs to judge the public value, including determining whether the behavior has public value, the legitimacy under the political and legal background, and the feasibility in management practice. Third, strengthen the negotiation and communication of stakeholders and identify the public value in complex public affairs. Public value is not only the sum of personal preferences, also the result of consultations between elected and appointed government officials, village officials and major stakeholders. Through the negotiation and communication of the main subjects of rural governance, find out the "greatest common divisor" of the value and goal of rural social public affairs, reduce conflict of value and goal, and generate the willingness and motivation for collaborative governance.

\subsection{Optimize the Design of the Collaborative Governance System to Reduce Institutional Resistance}

To realize the collaborative governance of the main body of rural governance, the collaborative governance system must be optimized. First of all, the "incentive compatibility mechanism"2 and cost sharing mechanism in economics can be introduced to solve the problem of asymmetry in the interests of rural gover${ }^{2}$ In market economy, every rational economic person will have a self-interest side, his personal behavior will act according to the rules of self-interest; if there is a kind of institutional arrangement to make the actor pursue personal interests, it coincides with the goal of maximizing collective value, which is "incentive compatibility". 
nance subjects. In the practice of rural governance, different governance entities inevitably carry their own legitimate interests. Incentive compatibility mechanisms can enable relevant subjects of rural governance to achieve the overall goal of collaborative governance while pursuing their own organizational goals. In addition, cost sharing mechanism needs to be established to effectively allocate governance costs. Second, build an effective leadership and coordination mechanism to solve cross-border organizations and cross-departmental issues. In China, the leading group mechanism within the Party committee and the government is an effective form of solving cross-border coordination. Give full play to the role of grassroots party organizations as a battle fortress, comprehensively enhance the comprehensive quality and comprehensive ability of grassroots party organizations to lead rural social governance, and provide organizational guarantees for the modernization of rural governance. Third, establish a social governance system and mechanism with consistent responsibilities and rights, matching affairs, finances and human resource, optimize rural governance authority, clarify the list of powers in rural governance, strengthen cooperation between departments and towns, straighten out the management mechanism of dispatched institutions, and provide grass-roots approval services and law enforcement standards; strengthen the service functions of rural society organization.

\subsection{Cultivate Individual Collaborative Behavior and Improve the Execution of Collaborative Governance}

In the practice of coordinated governance between governments and society in the world, all face a problem: the less public's enthusiasm for participation and the insufficient ability to participate in public affairs. From the perspective of behavioral, cultivating individual collaborative behavior not only requires optimizing the collaborative behavior of township civil servants and enhancing the governance capabilities of village cadres, also enhances and stimulates the public's willingness and behavior to participate in collaborative governance. First of all, the key to rural revitalization based on the revitalization of talents. It is necessary to cultivate village cadres with the characteristics of open thinking, patience and change orientation, strengthen conflict resolution and management capabilities. Moreover, it is also necessary to introduce college students to be village officials and encourage capable villagers to participant in rural public affairs. Optimize the main team of rural governance by attracting talents to return to their hometowns. Secondly, it is necessary to strengthen communication and coordination between the various subjects. Adhere to the principle of "party committee leadership, government support, CPPCC as a platform, participation of all parties, and service to the masses", invite village cadres, representatives of village sages and villagers' representatives to conduct consultations and discussions, encourage xiangxian ${ }^{3}$ participate in promoting rural moral construction

${ }^{3}$ Villages who have high moral character, talent, respected by other villagers, also have high social status in Chinese rural society. 
and social governance. Finally, there is a need to improve the public's ability to collaborate and promote orderly participation in rural social governance. Attach importance to rural elites, cultivate rural social organizations, provide diversified paths for them to participate in governance, support the establishment of rural councils represented by rural elites, and attract cultural celebrities in the countryside to participate in.

\subsection{Introduce Collaborative Technology and Collaborative Culture to Create a Good Collaborative Governance Environment}

Technology is the object of governance and the tool of governance. To create a good collaborative governance environment, collaborative technology and collaborative culture are essential. First, introduce big data and artificial intelligence to improve the rural information infrastructure, build a rural collaborative governance technology system to break through organizational barriers, and achieve information sharing and effective communication between rural governance entities. Integrate public data resources of government departments, integrate data held by various entities in rural governance, and form a shared big data resource library. Use new technologies to innovate governance methods and governance levels, and improve the scientific, effective and pertinence of rural governance decisions. Second, on the basis of the cooperative culture within the government, cultivate a culture of collaborative governance between the government and the private sector. Constantly reduce the differences in information and capabilities between various subjects, enhance the awareness and ability of rural social organizations, rural elites, and individual villagers to participate in rural governance, broaden participation channels and enhance supervision capabilities. With the development of economy and society, social forces have gradually broken through the traditional official-based culture and strong administrative inertia of rural society. Support and encourage rural communities to establish rural social organizations in accordance with the law, and actively cultivate a cultural atmosphere for rural social organizations to participate in collaborative governance. Cultivate the civic culture of rural society, catalyze the awakening of villagers' awareness and participation requirements, and increase the enthusiasm and participation of individual villagers in rural governance.

\section{Conclusion}

The grassroots society, especially the rural society, is the "last mile" to implement the policies of China. Traditional Chinese rural society is usually described by locality and immobility, but with the development of the economy and the acceleration of the urbanization process, the exchange between urban and rural have become more frequent, the cultural traditions and administrative inertia of rural society have gradually been broken, and the overall education level of the village has been continuously improved. With the development of the times, the problems faced by rural governance have become more complex, and the stake- 
holders involved have become more diverse. The traditional rural governance subject pattern can no longer adapt to the new changes of rural society. Therefore, under the strategy of rural revitalization, only by constructing a new pattern of collaborative participation of multiple subjects in rural governance, and relying on rational and orderly rural governance, we can continue to promote the modernization of grassroots governance.

\section{Conflicts of Interest}

The author declares no conflicts of interest regarding the publication of this paper.

\section{References}

Li, Y. H. (2015). The Dual Transformation of Rural Governance and Villager Autonomy. Zhejiang Social Sciences, 12, 76-81. (In Chinese)

Moore, M. H. (1995). Creating Public Value: Strategic Management in Government. Cambridge: Harvard University Press.

Xu, Y. (2002). County Government, Township School, and Village Governance: Structural Transformation of Rural Governance. Jiangsu Social Sciences, 2, 27-30. (In Chinese)

Yin, M. E (2016). Diversity and Synergy: The Path Choice of Constructing New Type of Rural Governance Subject Relations. Jianghuai Forum, 6, 46-50. (In Chinese)

Yu, K. P. (2000). Governance and Good Governance. Beijing: Social Sciences Archives Publishing House, 67. (In Chinese)

Zhang, C. M. (2017). Research on the Practice and Value of New Social Organizations Participating in Rural Governance: Based on the Experience of the Construction of the Yinjiang Village Council in Guizhou. Postgraduate Journal of Central China Normal University, 24, 36-40. (In Chinese)

Zhou, X. G., \& Ai, Y. (2010). Institutional Changes under Multiple Logics: An Analytical Framework. Chinese Social Sciences, 4, 132-150+223. (In Chinese) 